\title{
Neuroinflammation and microglia/macrophage phenotype modulate the molecular background of post-stroke depression: A literature review
}

\author{
ELŐD ERNŐ NAGY ${ }^{1}$, ATTILA FRIGY ${ }^{2}$, JÓZSEF ATTILA SZÁSZ ${ }^{3}$ and EMŐKE HORVÁTH ${ }^{4}$
}

\begin{abstract}
${ }^{1}$ Department of Biochemistry and Environmental Chemistry, 'George Emil Palade' University of Medicine, Pharmacy, Science and Technology of Targu Mures, 540139 Targu Mures; ${ }^{2}$ Department of Internal Medicine IV,

'George Emil Palade' University of Medicine, Pharmacy, Science and Technology of Targu Mures,

540103 Targu Mures; ${ }^{3}$ Neurology Clinic II, 'George Emil Palade' University of Medicine, Pharmacy, Science and Technology of Targu Mures, 540136 Targu Mures; 'Department of Pathology, 'George Emil Palade' University of Medicine, Pharmacy, Science and Technology of Targu Mures, 540139 Targu Mures, Romania
\end{abstract}

Received May 6, 2020; Accepted June 5, 2020

DOI: $10.3892 / \mathrm{etm} .2020 .8933$

\begin{abstract}
Increasing evidence hints to the central role of neuroinflammation in the development of post-stroke depression. Danger signals released in the acute phase of ischemia trigger microglial activation, along with the infiltration of neutrophils and macrophages. The increased secretion of proinflammatory cytokines interleukin (IL)-1 $\beta$, IL-6, IL-8, and tumor necrosis factor $\alpha$ (TNF $\alpha$ ) provokes neuronal degeneration and apoptosis, whereas IL-6, interferon $\gamma$ (IFN $\gamma$ ), and $\mathrm{TNF} \alpha$ induce aberrant tryptophane degradation with the accumulation of the end-product quinolinic acid in resident
\end{abstract}

Correspondence to: Dr Előd Ernő Nagy, Department of Biochemistry and Environmental Chemistry, 'George Emil Palade' University of Medicine, Pharmacy, Science and Technology of Targu Mures, 38 Gheorghe Marinescu Street, 540139 Targu Mures, Romania

E-mail: elod.nagy@umfst.ro

Abbreviations: AMPA, $\alpha$-amino-3-hydroxy-5-methylisoxazole-4propionic acid; Arg-1, arginase-1; ATP, adenosine triphosphate; BDNF, brain derived neurotrophic factor; CCL, chemokine (C-C motif) ligand; CD, cluster of differentiation; HMGB1, high mobility group box 1; Hsp, heat shock protein; GM-CSF, granulocyte-macrophage colony-stimulating factor; IFN, interferon; IL, interleukin; IRF, interferon regulatory factor; Ly6, lymphocyte antigen 6; Iba-1, ionized calcium-binding adaptor molecule 1; iNOS, inducible nitric oxide synthase; MCAO, middle cerebral artery occlusion; M-CSF, macrophage colony-stimulating factor; MHCII, major histocompatibility complex II; miRNA, micro RNA; MMP, matrix metalloproteinase; MSR-1, macrophage scavenger receptor-1; NeuN, hexaribonucleotide binding protein-3; NMDA, N-methylD-aspartate; OPG, osteoprotegerin; PRX, peroxiredoxin; RANKL, receptor activator of nuclear factor- $\kappa \mathrm{B}$ ligand; TGF, transforming growth factor; TNF, tumor necrosis factor; UTP, uridine triphosphate

Key words: neuroinflammation, pro-inflammatory cytokines, glutamate excitotoxity, post-stroke depression, M2 macrophage glial cells. This promotes glutamate excitotoxicity via hyperexcitation of N-methyl-D-aspartate receptors and antagonizes 5-hydroxy-tryptamine, reducing synaptic plasticity and neuronal survival, thus favoring depression. In the post-stroke period, CX3CL1 and the CD200-CD200R interaction mediates the activation of glial cells, whereas CCL-2 attracts infiltrating macrophages. CD206 positive cells grant the removal of excessive danger signals; the high number of regulatory T cells, IL-4, IL-10, transforming growth factor $\beta$ (TGF $\beta$ ), and intracellular signaling via cAMP response element-binding protein (CREB) support the M2 type differentiation. In favorable conditions, these cells may exert efficient clearance, mediate tissue repair, and might be essential players in the downregulation of molecular pathways that promote post-stroke depression.

\section{Contents}

1. Introduction: Systemic and neuroinflammation are both characteristic in certain forms of post-stroke depression

2. Post-stroke depression, genetic factors and lesion localization

3. Brain-derived neurotrophic factor: A link between purinergic signaling, neuroinflammation and depression

4. The post-stroke immune pathways and tissue repair

5. The microglia/macrophage network in post-stroke depression

6. Mediators of neuroinflammation are key elements in the post-ischemic response

7. Experimental evidence for pharmacological checkpoints of inflammation

8. Discussion

1. Introduction: Systemic and neuroinflammation are both characteristic in certain forms of post-stroke depression

Stroke is a medical emergency that frequently results in severe neurological sequelae and other complex dysfunctions. Among these, post-stroke depression (PSD) is prevalent, being 
experienced by about one-third of stroke patients $(1,2)$. PSD diminishes the quality and expectancy of life through multiple factors: Cognitive decline, high rate of suicide, increased risk of falls, functional impairment, and poor response to rehabilitation (3). Depression not only decreases the quality of life of those affected, but it is also associated with a shorter interval to recurrent stroke and higher mortality $(4,5)$.

There are many hypotheses about the underlying molecular pathways of depressive disorders: the monoamine neurotransmitter hypothesis, the hypothalamus-pituitary-adrenal axis dysfunction hypothesis, the neurotrophic hypothesis, and the neuroinflammation hypothesis. These hypotheses are complementary rather than contradictory and probably address distinct features of the same multi-faceted disease.

Substantial evidence supports the dominant presence of inflammation in depressive disorders (6), especially the so-called atypical depression, which can be characterized by fatigue, increased appetite, weight gain, hypersomnia, hypoactive hypothalamus-pituitary-adrenal axis, altered metabolism of the frontoparietal cortex, and a high association with fibromyalgia and chronic fatigue syndrome (7). In atypical depression, signs of systemic inflammation have been detected: higher circulating levels of C-reactive protein, interleukin-1 $\beta$ (IL-1 $\beta$ ), and tumor necrosis factor $\alpha$ (TNF $\alpha$ ) along with the dominance of IL-2 positive Th1 lymphocytes. Along with increased circulating proinflammatory cytokines, the presence of the typical systemic acute-phase reaction has been described (8). The activation of proinflammatory mediators perpetuates the oxidative and nitrosative stress in the central nervous system, with the consumption of n-3 polyunsaturated fatty acids, glutathione, coenzyme Q10, and, in general, antioxidant capacity; this activity triggers pronounced changes in 5-hydroxytryptamine and N-methyl-D-aspartate (NMDA) signaling (6).

According to considerable evidence, pro-resolving macrophages, often labeled as M2 type cells, play a distinct role in the clearance of the perished tissue, exert tissue repair, and may rewire survivor neurons. However, the phenotype of these cells is yet incompletely characterized (9). Despite indirect evidence, the putative role of M2 type macrophages in post-stroke depression has not been analyzed previously. In this narrative review, we present mostly experimental, but, in some cases, human data to describe the regulatory processes of the post-stroke period. We concatenated information clusters concerning the role of neuroinflammation in purinergic stress, altered glutamatergic signaling, neuroprogression, suggesting that M2 type macrophages might feature as prominent scavenger and reparatory actors in post-stroke depression.

\section{Post-stroke depression, genetic factors and lesion local- ization}

PSD is characterized by mood disorders with depressive features or major depressive-like episodes (10). Genetic factors, location of the lesions, and grade of post-stroke physical and intellectual disability influence the severity and duration of PSD. Among genetic factors, the serotonin-transporter-linked polymorphic region 5-HTTLPR and solute carrier family 6 member 4 STin2VNTR polymorphisms of the serotonin transporter gene and hypermethylation of the 5-HTTLPR s/s genes have been associated with the onset and duration of
PSD (10). Association of PSD with stroke localized to specific brain regions was postulated many years ago (11). According to some observations, lesions proximal to or in the frontal pole, or the limbic area, were more frequently associated with PSD $(12,13)$, but other studies failed to confirm these topological correlations $(14,15)$. Although lesion volume reportedly has predictive value for the outcome, contradictory results have been published (16-20). Other studies correlated PSD with lesions of the medial prefrontal cortex, thalamus, amygdala, or pallidum by defining the disruption of frontal cortico-limbic neuronal circuits $(18,21,22)$. Recent pioneering studies performed by voxel-based symptom lesion mapping could not resolve the ambiguity; however, two groups confirmed the correlation of PSD severity with dorsolateral prefrontal and left cerebellar hemispheric localization (20,23,24).

Physical disability may be in part caused by PSD, but at least in some patients, the disability and PSD are independently associated with the primary event (25).

There is poorly known, whether PSD, as an outcome has common or different underlying molecular pathways in different topological involvements. Neurotrophic factor-related findings translate, at least in some degree, divergence dependent on lesion localization.

\section{Brain-derived neurotrophic factor: A link between puri- nergic signaling, neuroinflammation and depression}

Brain-derived neurotrophic factor (BDNF) is a growth factor member of the neurotrophin family that is essential for neuronal development, survival, and plasticity. BDNF plays an important, differential modulatory role in the development and evolution of mood disorders; depression and stress are accompanied by low levels of neurotrophic factor and dendritic atrophy in the hippocampus and prefrontal cortex whereas high-level, transient stress-induced synthesis is characteristic of individual nuclei of the amygdala and nucleus accumbens (26). From experimental work and clinical studies (which focused on neurological disorders such as traumatic injury, Parkinson's disease, multiple sclerosis, and neuropathic pain), it is known that BDNF is synthesized not only in neurons and astrocytes but also in microglia (27-31).

BDNF mRNA levels were reportedly decreased in the dentate gyrus and hippocampus of rats exposed to the chronic stress of prolonged immobilization (32). The Val66 $\rightarrow$ Met66 point-mutation that causes deficient BDNF secretion increases susceptibility to anxiety, depression, and bipolar disorder $(33,34)$. It has also been found that antidepressant treatment increases the synthesis of BDNF, and a neurotrophic hypothesis of depression has been reported (35). In rat models, many kinds of older or newer antidepressant medications, e.g., monoamine oxidase inhibitors, selective serotonin reuptake inhibitors, tricyclic agents, specific serotoninergic drugs, electroconvulsive shock therapy, and transcranial magnetic stimulation, trigger increased production of BDNF. In patients with major depression, low values of BDNF in serum, plasma, and platelets have been reported $(36,37)$. Circulating BDNF is at least partially produced in the brain, and it can pass the blood-brain barrier (38). Treatment with selective serotonin reuptake inhibitors as well as serotonin and norepinephrine reuptake inhibitors has been reported to raise plasma BDNF 
levels, and the molecule has been designated as a biomarker for antidepressant therapy $(37,39)$. BDNF has differential effects in various regions of the brain in depression: whereas it is diminished in the prefrontal cortex and the hippocampus, it is also implicated in malfunctioning of the depression-related mesolimbic reward center, which is the ventral tegmental area-nucleus accumbens dopaminergic circuit; administration of exogenous BDNF in this area induces depressive-like symptoms. Phasic activity of dopaminergic neurons in the ventral tegmental area-nucleus accumben region triggers BDNF in stressed mice $(40,41)$. In an experimental stroke, a 2-fold rise of BDNF expression was found in the ischemic core region, which gradually decreased to the reference level at seven days (42).

The synthesis and release of BDNF in microglia appear to be tightly associated with the activation of ATP-sensitive purinergic receptors, especially P2X4R. During a stroke, dying neurons and other cells from the ischemic region release ATP, which addresses the transmembrane $\mathrm{P} 2 \mathrm{X} 4$ purinergic receptors of glial cells. Upregulation of these receptors accompanies microglial activation, $\mathrm{P} 2 \mathrm{X} 4 \mathrm{R}$-triggered resident microglia, and infiltrating macrophages, which are important sources of pro-inflammatory cytokines and mediators of the post-stroke immune response $(43,44)$. Activated P2X4R facilitate the release of BDNF from these cells (30). Verma et al (45) created global and myeloid-specific P2X4R null mice and subjected them to transient occlusion of the middle cerebral artery. The authors found upregulation of PX4R on neurons in wild-type animals, especially on microglia. In female mice with global receptor deletion, the volumes of cortical and hemispheric infarcts were significantly smaller and the recovery better than in controls and their male littermates. However, the myeloid-specific P2X4R knock-out had different effects: besides a quick sensorimotor recovery, the animals of both sex had anhedonia and depressive-like behavior along with high expression of IL- $1 \beta$, IL- 6 and TNF $\alpha$; low BDNF mRNA in the perilesional cortex; and low plasma titers of the cytokines (45). These results indicate that the global deletion of the $\mathrm{P} 2 \mathrm{X} 4$ receptor is neuroprotective and suspends neuroinflammation, but when deletion affects only the microglia favors a depression-prone and pro-inflammatory phenotype. One possible reason for this dichotomy is that microglia lacking $\mathrm{P} 2 \mathrm{X} 4$ possesses low BDNF synthesizing capacity.

\section{The post-stroke immune pathways and tissue repair}

A short overview of the post-stroke immune response. The immune system is thought to play a critical role in the course and the main outcomes in PSD (46). Recent data suggest that PSD is related to complex immune deregulation: immunosuppression, neuroinflammation, and a characteristic shift in microglia/macrophage phenotype in the lesional area. After the onset of stroke, injured neurons and glial cells quickly activate the neighboring astrocytes through the expression of damage-associated molecular patterns (high mobility group box-1, HMGB1; peroxiredoxins, PRX; galectin-3) (47). These cells, along with resident microglia, secrete a set of pro-inflammatory cytokines (IL-1 $\beta$, IL-6, IFN $\gamma, \mathrm{TNF} \alpha$ ), chemokines, and matrix metalloproteinases, like MMP-9, contributing to the disruption of the blood-brain barrier (48).
Neuronal-derived fractalkine (CX3CL1) further amplifies microglia activation. IL-1 $\beta$, TNF $\alpha$, and complement $\mathrm{C} 1 \mathrm{q}$ secreted from microglia trigger reactive astrogliosis with the appearance of A1 type cells, which manifest high expression of genes associated with neuronal damage and death, such as Neutrophil gelatinase-associated lipocalin (Lcn2) and Serine protease inhibitor A3N (Serpina3n) (49). Oligodendrocytes are also affected by ischemia, losing their capacity to remyelinate neuronal axons. Neutrophils are attracted by various chemokines, i.e. CCL2,9,10,11,20; their accumulation in the lesional zone reportedly worsens the clinical outcomes (47). With a close shift, monocyte-derived macrophages pass through the injured blood-brain barrier, penetrate the core lesion and also deploy at the perilesional zone, the penumbra. Peripheral monocytes are recruited through monocyte chemoattractant protein (MCP-1 or CCL-2), and due to danger signals received from the environment, switch to a pro-inflammatory phenotype, releasing various metalloproteinases and reactive oxygen species (48). In the chronic recovery phase, in an IL-4, IL-10, and transforming growth factor $\beta$ (TGF $\beta$ ) containing milieu, infiltrating macrophages may switch their differentiation path to an anti-inflammatory phenotype. IL-4 released from injured neurons mediates this transition through the interferon regulatory factor (IRF)-4 signaling (50).

Astrocytes also orchestrate the adaptive immune response and T-cell invasion of the ischemic region, occurring 3 days to 1 month after stroke. IL-15 signaling increases the number of $\mathrm{CD}^{+}$cytotoxic $\mathrm{T}$ cells and also the invasion of natural killer lymphocytes, which is a detrimental effect (51). Th17 cells are also over-represented and activated (52). Recent studies underscore the central role of $\mathrm{CD}^{+} / \mathrm{CD} 25^{+} / \mathrm{Foxp}^{+}$or $\mathrm{CD} 4^{+} / \mathrm{CD} 25^{+} / \mathrm{CD} 127^{-}$regulatory $\mathrm{T}$ cells, which proliferate and are detectable in ischemic lesions up to 30 days $(48,53)$. A high number of Tregs at $48 \mathrm{~h}$ is associated with the right functional outcome; reversely, a decreased number indicates a higher probability for early neurological deterioration $(53,54)$. Tregs also provide neurovascular protection through the downregulation of MMP-9, but this effect depends on their IL-10 synthesizing capacity. IL-10 producer Tregs are susceptible to antagonize IFN $\gamma$ and TNF $\alpha$ (55). B lymphocytes are also detectable in the invader cell populations; as B-cell deficient mice show larger infarct volumes and more severe neurological deficit, their role seems to be somewhat protective, especially in the presence of IL-10 (48). However, it was also documented that B-cells and autoantibodies probably induce delayed cognitive deficit and dementia (56).

Molecular processes and tissue repair in immediate and subacute phase of post-stroke recovery. The timeline of the post-stroke immunological response has been sketched by Rayasam et al (57). They proposed four consecutive but functionally interweaving phases: Innate immune response, adaptive immune response, and resolution. Immediately after the ischemic event, reactive oxygen species, heat shock proteins, and nucleoside triphosphates (ATP, UTP) are released from the ischemic tissue. Two important danger signals appear: HMGB1 promotes the breakdown of the blood-brain barrier, and peroxiredoxins quickly activate the Toll-like receptors of myeloid cells (58). As a result of these actions, the innate immune response is initiated, and 
post-synaptic NMDA and $\alpha$-amino-3-hydroxy-5-methylisoxazole-4-propionate (AMPA) receptors are stimulated. NMDA receptors are cation influx regulators, which support neuronal health, especially synaptic plasticity, that is necessary for learning and memory. In ischemia, in contrast to these useful activities, a dichotomous behavior was observed: overactivation of NMDA receptors mediates glutamate excitotoxicity; however, AMPA receptors foster synaptic plasticity and long-term potentiation $(40,59)$. Some heat shock proteins, such as Hsp70 and Hsp27, seem to promote neuronal survival, whereas Hsp32, known as heme oxygenase (HO-1), might have a dual role reacting with ferrous ions and production of hydroxyl radicals (pro-oxidant), but inhibiting lipid-peroxidation and lowering neuronal apoptosis, if overexpressed (anti-oxidant) $(60,61)$. These proteins, together with other free radicals, induce mitochondrial failure and apoptosis. Immediately after the injury, resident microglia and astrocytes are activated, followed by the infiltrating neutrophils (which likely appear in the first hour) (62) and an increasing proportion of mononuclear/macrophage cells of myeloid origin. Microglia and infiltrating macrophages are receptive to distinct chemotactic signals: the former react to CX3CL1 (fractalkine) and the latter to CCL2 proteins. In the past, the two species could not be phenotypically differentiated, but nowadays, they can be distinguished based on their Ly6C, CD45, or transmembrane protein 119 expression $(63,64)$. In the subacute phase of recovery, M2 type microglia secrete neurotrophic factors, such as TGF $\beta$ or IGF, remove disabled synapses and prevent the degradation of the extracellular matrix through arginase-1 (Arg1). Pro-resolving macrophage subspecies expressing the macrophages scavenger receptor-1 (MSR-1 or CD206) are responsible for the clearance of HMGB1 and PRX (65).

Cell survival and salvage signals in the ischemic region. Surprising results were disclosed concerning distinct ways of cell death and survival in stroke. Jiang et al (42) applied a focal ischemic and embolic stroke model to identify survivor cells in the core lesion of strokes. Using TUNEL assay and caspase-3 staining, they found a mixed form of cell death, with the emergence of intense apoptosis and autophagy in addition to necrosis. They also found that $>80 \%$ of the cells in the core were macrophage/microglia and that among ionized calcium-binding adapter molecule-1 (Iba-1) positive cells, viable NeuN-positive elements coexisted even days after the ischemic event (42). It has been proposed that early regulatory signals, such as IL-4 and miRNA-124 $(66,67)$, which are emitted by damaged neurons, favor the rapid formation of M2 type resolving microglia/macrophages. Phosphatidylserine exteriorization of neurons is a strong phagocytotic signal, that is divisive for M1 and M2 type cells. The first, emitting high concentrations of reactive oxygen species, oxidize membrane phosphatidylserine molecules often destroying not only dead, but also viable neurons; the second react instead to chemically unmodified, but exteriorized phosphatidylserine, recognizing it like a classical, 'eat me signal' (66).

M2 type microglia produce higher levels of F-actin, being more inclined to phagosome formation, clear the irreversibly damaged structures by phagocytosis, while M2 type infiltrating cells also show intense phagocytosis, releasing anti-inflammatory cytokines, mainly IL-4, IL-10 and TGF $\beta(57,66)$. These cytokines exert direct and indirect protective roles: IL-10 is a negative regulator of IL-1 $\beta$, IL-6 and TNF $\alpha$, whereas TGF $\beta$ manifests neuroprotection through the synthesis of nerve growth factor (NGF) and upregulation of anti-apoptotic proteins, such as Bcl-2 and Bcl-x1 (66).

In C57BL IL-4 knockout mice, the lack of IL-4 turned on M1 type differentiation: When IL-4 was administered, the balance was reversed and M2 type cells dominated; moreover, IL-4 was beneficial in long-term functional recovery (68). Liesz et al (55) proposed a strong interaction between invader leucocytes and resident microglia. They observed that in perforin deleted mice, anti-CD49d therapy inhibited not only leukocyte migration in the lesional area but also a significant reduction of Iba- $1^{+}$microglia cell counts and IFN $\gamma$ secretion, along with a robust reduction of the infarct volume. IL-10-expressing regulatory $\mathrm{T}$ cells also help M2 type macrophage/microglia differentiation through activation of glycogen synthase kinase $3 \beta$ and a phosphatase and tensin homolog (69).

The essential signaling interactions and the multicellular modulation of tissue repair are shown in Fig. 1. Titova et al (70), using functional neurological tests and magnetic resonance imaging, investigated the late-phase effects of middle cerebral artery occlusion (MCAO) on proton-irradiation preconditioned rats. On post-stroke day 7 (which by extrapolation corresponds to 7-8 months for humans), T2 tissue relaxation scores and neurological severity scores were correlated and characterized the late-stage brain recovery (intensive neovascularization, the presence of Von Willebrand factor/glial fibrillary acidic protein-positive glio-vascular complexes, enhanced neuronal viability, and decreased numbers of phagocytes).

\section{The microglia/macrophage network in post-stroke de- pression}

The macrophage theory of depression, polarization and the classification dilemma. Applying histochemical analysis and computer-assisted stereological cell counting, Ongür et al (71) discovered that microglial density in the subgenual prefrontal cortex, especially in the Brodman's 24, is reduced in patients with major depressive and bipolar disorder. Resident microglia constitute $\sim 5-12 \%$ of all central nervous system cells; they derive from myeloid precursors of the embryonic yolk sac. Studies performed with in vivo two-photon imaging technology confirmed that in the resting form, microglia continuously monitor the microenvironment, emitting numerous protrusions (72). Microglia are especially susceptible to danger signals, which transform them to a reactive phenotype, characterized by the shortening of cellular processes and swelling and enlargement of the soma; in the extreme form they have an ameboid appearance, completely lacking cellular processes (59).

Smith (73), in 1991, proposed the macrophage theory of depression, invoking the role of pro-inflammatory signals, cytokines, hormones and various causes of macrophage activation, such as infection, allergy or systemic autoimmune disease. In his medical hypothesis, he mentioned the high prevalence of depression in post-stroke patients with atherosclerotic background, and he proposed a primary role for the 


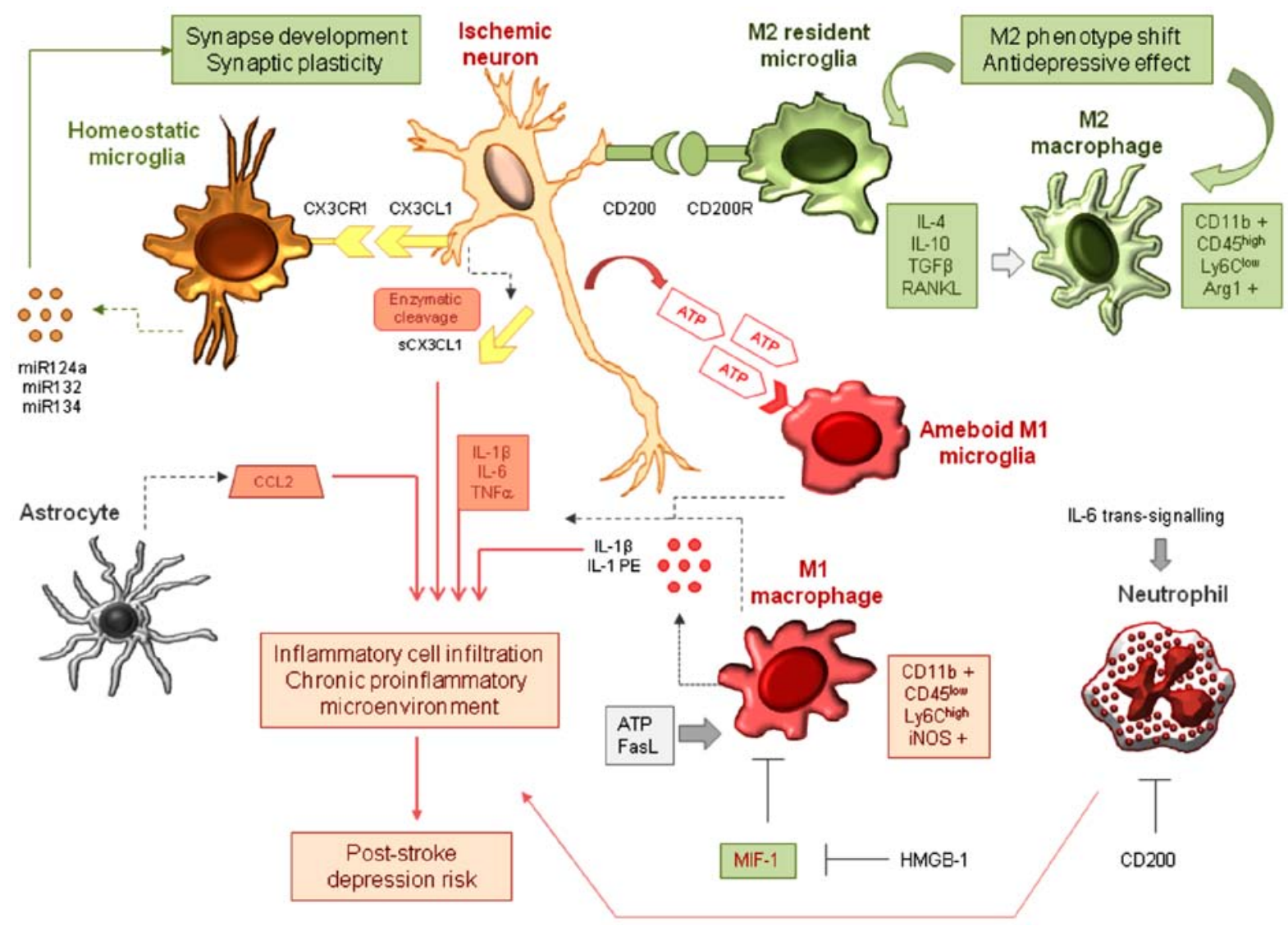

Figure 1. Generation and multi-cellular modulation of the proinflammatory environment in post-stroke depression. ATP released from injured neurons acts as a danger signal and alerts the surrounding microglia via P2X4 purinergic receptors, triggering M1-type microglial activation and ameboid transformation. These cells, together with the infiltrating M1-type macrophages release IL-1 $\beta$, IL-6, TNF $\alpha$, and other pro-inflammatory mediators, partially in microvesicles and exosomes. Soluble CX3CL1 generated by metalloproteinase-mediated cleavage enhances the invasion of inflammatory cells, along with CCL2 released by astrocytes. Two receptor-ligand interactions between neurons and microglia control neuronal survival and regeneration. Membrane-bound CX3CL1 coupling to CX3CR1 maintains synaptic plasticity, contributes to synapse development and keeps microglia in a surveyor state. CD200-CD200R signaling determines a phenotype shift towards M2-type microglia. miR-124a, miR-132, and miR-134 are released from homeostatic microglia and facilitate neuronal survival. M2 phenotype switch is protective, but insufficient M2 activity together with MIF-1 may cause the perpetuation of the pro-inflammatory microenvironment and may contribute to the development of post-stroke depression. IL, interleukin; TNF $\alpha$, tumor necrosis factor $\alpha$.

quickly activated IL-1 producers, monocytes and microglia. $\mathrm{He}$ also argued for the strong inhibitory role of $\mathrm{n}-3$ polyunsaturated fatty acids on IL-1 and TNF $\alpha$ secretion by macrophages, cardiovascular events and depression in Japan (73).

The M1-M2 concept of macrophage differentiation originates from observations made in macrophages obtained from C57BL/6 and Balb/c mice (9). The two sub-species can be differentiated by their arginine metabolism: M1 cells convert L-arginine to nitric oxide by inducible nitric oxide synthase, whereas the M2 type expresses Arg1 and produces mainly citrulline. Other relevant end-products in the latter are polyamines and proline, necessary for tissue repair and extracellular matrix regeneration. The M2 type cells downregulate their MHCII molecules, thus decreasing antigen presentation (74). These observations suggest an overt pro-inflammatory role for $\mathrm{M} 1$, and, in contrast, pro-resolving abilities for M2 cells.

Macrophage polarization nowadays seems to be a more complicated process than it was initially modeled. According to a newer classification, M2 type cells include three functionally different subtypes: M2a produces anti-inflammatory and trophic factors, M2b has transitional phenotype between M1 and M2a, whereas M2c are primarily phagocytes and suppress the innate immune system (74). Xue et al (75) differentiated macrophages in the presence of GM-CSF or M-CSF, applying in the second phase of differentiation 28 different stimuli to analyze their transcription patterns. They found that when IFN $\gamma+$ TNF $\alpha$ or IL-10 were added, the cells maintained their differentiation paths along the M1/M2 axis. However, when adding stimuli not directly linked to the M1/M2 polarization, they registered a whole spectrum of transcriptional signatures and suggested that many different macrophage phenotypes may exist (75). Also, it turned out that relevant markers of M1 or M2 type activation are somewhat overlapping: Arg1 expression is strongly upregulated after IL-4 stimulation, which also elicits weak iNOS2 expression, whereas (lipopolysaccharide) LPS or LPS + IFN $\gamma$ administration also provoke Arg1 slightly (9). Moreover, the gene expression signatures of the in vivo LPS-non-responsive $\mathrm{M} 2$ and in vitro alternatively (IL-4) stimulated macrophages are only partially shared. Common regulatory pathways comprise proliferation, apoptosis, differentiation, and arginine metabolism (both express Arg1) (76). Two transcription factors competing for the same activators are responsible for the M1/M2 phenotype switch: cAMP response element-binding protein (CREB) and nuclear factor- $\kappa \mathrm{B}$ (NF- $\mathrm{\kappa B}$ ) both link to C/EBP and CBP/p300; CREB mediates the M2 type, while NF-kB transmits M1 type 
differentiation. Gsk3 $\beta$ activates $\mathrm{NF}-\kappa \mathrm{B}$, but inhibits CREB; PI3Akt suspends the activation of Gsk3 $\beta$, thus pushing the differentiation balance to the M2 phenotype (66).

Some authors even argue that the M1 vs. M2 nomenclature is useless since there is a significant overlap in their transcriptional profiles, which show no hint of differentiation-organizing value (77). The nomenclature guidelines now recommend the exact definition of activators and the use of multiple markers of activation to characterize the phenotype (9).

Homeostatic regulatory loops and imbalance in ischemia. Growing evidence highlights the existence of bidirectional, versatile communication between neurons and resident microglia in the animal and human brain. Neurons regulate microglia through specific ligands, such as CD200 and CX3CL1 (fractalkine), which attach to their receptors, CD200R, and CX3CL1R. Neurons seem to influence both the basic and activated state of microglia also by classical neurotransmitters, e.g., glutamate, and $\gamma$-aminobutyric acid $(59,78)$. Modulation of CD200 signaling was proposed to promote a phenotype shift of macrophages towards the arginase-1 producer, reparatory M2 subtype, through the cAMP-responsive element-binding protein-C/enhancer-binding protein- $\beta$ (CREB-C/EBP- $\beta$ ) signaling pathway. Ligand-binding to the CD200 receptor tyrosine-based inhibitory ITIM-motifs suppresses downstream signaling through Src homology 2 domain-containing phosphatase 1 and inhibits the danger-signaling through the pattern recognition receptors, thus suppressing the development of the inflammatory medium. In parallel, microglia release neurotrophic factors and downregulate the expression of MHC II, $\mathrm{CD} 45$, and $\mathrm{Fc}$ receptors (74). In this scene, microglia show the M2 phenotype, halt antigen presentation and stay in quiescent surveillance of their microcosmos. CD200-Fc treatment of lipopolysaccharide-triggered rat macrophages upregulates M2 cells while downregulating the M1 subtype and IL-1 $\beta$, IL-6 and G-CSF (79).

Cerebral ischemia changes this equilibrium dramatically. In ischemic conditions, CD200 expression of neurons is reversely related to their viability, while CD200R is upregulated in microglia (59). This time, the monocyte-macrophage network work as a reliable sensor for many damage-associated, homeostasis-spoiling messengers. Xu et al (80) recently reported that elevated levels of plasma macrophage migration inhibitory factor-1 (MIF-1) are a risk for post-stroke depression. MIF-1 is produced in the pituitary gland constitutively, but especially in response to the stress of inflammatory stimuli $(81,82)$. The transcription factor of a danger signal, HMGB1, is a repressor of MIF-1 and can be targeted by microRNA19a, which has similar effects of MIF-1, i.e., promotion of vascular inflammation and foam-cell formation in the atherosclerotic vessel wall (83). Ischemic stroke is associated with the emergence of neoantigens in the brain, and the myelin-specific, T-cell-mediated immune response is detrimental in the long-term post-stroke period (57). According to Meng et al (85), ATP and FasL in parallel induce the M1 macrophage phenotype, with the secretion of IL-1 $\beta$ and MMP-3/MMP-9, and activated microglia contribute to the inflammatory microenvironment with the production of TNF $\alpha$ and reactive oxygen species (84). Pro-inflammatory signals also act via positive feed-back loops: extracellular ATP stress induces the pattern recognition receptors and triggers $\mathrm{NF}-\kappa \mathrm{B}$ signaling, which results in IL-1 $\beta$, IL-18, and Nod-like receptor pyrin 3 (NLRP3) transcription. Further, inflammasome NLRP3 facilitates the caspase-1-mediated enzymatic cleavage of pro-IL-1, amplifying the pro-inflammatory milieu (74).

Microglia, M1- and M2 type macrophages can be differentiated in brain tissue. Zarruk et al (64) applied permanent MCAO on LysM-EGFP (bearing EGFP inserted into the lysosome M locus) knock-in transgenic mice. According to their setting, microglia can be identified as $\mathrm{CD}_{1} 1^{+} / \mathrm{CD} 45^{+} / \mathrm{Ly} 6 \mathrm{G}^{-} / \mathrm{LysM}^{-}$EGFP $^{-}$cells, while macrophages are $\mathrm{CD} 1^{+} / \mathrm{CD} 45^{+} / \mathrm{Ly} 6 \mathrm{G}^{-} / \mathrm{LysM}^{-} \mathrm{EGFP}^{+}$elements. The authors showed differential expression of Arg1 (1000X higher in macrophage) and IL-1 $\beta$ (90X increased in macrophages compared with microglia). Wattananit et al (86) performed interesting long-term follow-up experiments to differentiate between resident microglia and infiltrating macrophage effects in cerebral ischemia: They generated chimeric CX3CR1-GFP mice and used them as bone-marrow and monocyte donors for transplantation to whole-body irradiated (except the head) CD57BL animals subjected to MCAO. They found that GFP-positive bone marrow-derived macrophages invaded the ischemic lesion and expressed a predominant pro-inflammatory Ly6 $\mathrm{C}^{\text {high }}$ phenotype at three days, then switched to an anti-inflammatory Ly6 $\mathrm{C}^{\text {low }}$ preponderance at seven and 14 days, when the cells also highly expressed BDNF. At seven days, both pro-inflammatory (IL-1 $\beta$, IL-6, TNF $\alpha$ and NOS) and anti-inflammatory (TGF $\beta$, CXCL13 and CD163) gene expressions were high in hemicerebral tissue homogenates, but at 14 days only the anti-inflammatory set remained upregulated. Selective monocyte depletion with the anti-MCP-1 antibody at a late stage (seven weeks) impaired behavior in functional-staircase and corridor tests, while repressing TGF $\beta$ and CD163 at the late stage. These results indicated that early infiltration of monocytes in the injured brain is critical for efficient long-term recovery (86). Horváth et al (87) recently reported that microglia/macrophages participate in the cellular infiltrate of the ischemic rat brain $24 \mathrm{~h}$ after transient MCAO, both in the ischemic core and the surrounding penumbra zone; in the core lesion, inducible nitric oxide synthase 2-positive microglia/macrophages dominated, whereas Arg1-positive cells in the penumbra were upregulated.

Microglial microvesicles and exosomes in neuroinflammation. Exosomes are membrane-derived, secreted globular complexes of small diameter, typically 30-100 nm. Microvesicles are larger, 100-1,000-nm particles that are shed from a variety of cells (88). Microvesicles have been proposed as biomarker vehicles in stroke; however, due to their heterogeneity and methodological limitations, they have been, until recently, the subject of only small-scale clinical studies. Endothelial microvesicles reportedly generate in vitro angiogenesis in an oxidative stress-dependent manner (89). Both exosomes and microvesicle deliver a complex molecular burden: membrane and cytosolic proteins, messenger RNA, and miRNA. Leroyer et al (90) demonstrated that microvesicles obtained from the apoptotic or IL- $1 \beta$-triggered endothelial cells of the ischemic limb promote endothelial differentiation of bone-marrow-derived mononuclear cells, 
whereas particles obtained from atherosclerotic plaques are ineffective. In a stroke, reactive microglia secrete exosomes and microvesicles containing IL-1 $\beta$, IL- $1 \beta$ processing enzyme, and the ATP-sensitive P2X7 receptor. Besides containing soluble factors, these vesicle-packed mediators also propagate neuroinflammation. Microvesicles possess a complex signature of miRNAs, consisting of hundreds of regulatory molecules, among which miR-132 and miR-134 supervise synaptic plasticity, and miR-124a responds for axonal outgrowth in regenerating neurons. In the prefrontal cortex of depressive patients, the vesicle-encapsulated miR-1202 powerfully interferes with glutamatergic/dopaminergic signaling (88). Moreover, in the peripheral monocytes of major depressive patients' specific signatures were described with increased miRNA-26b, miRNA-1972, miRNA-4485, miRNA-4498 and miRNA-4743; the predicted target genes were linked to biological processes probably involved in depression, including axon guidance and extension, synaptic transmission, learning and memory (88).

ATP triggered increased secretion of microvesicles containing specific mRNA transcript sets for the parental pool in IL-4 vs. IFN $\gamma$ and lipopolysaccharide-treated M1- and M2 type peritoneal macrophages (91). Upon ATP stimulation, macrophages and microglia released IL-1 $\beta$ and elements of the inflammasome $(91,92)$.

\section{Mediators of neuroinflammation are key elements in the post-ischemic response}

Pro-inflammatory cytokines and neuroprogression in cerebral ischemia. Substantial evidence indicates that classic pro-inflammatory cytokines induce neuroprogression (neurodegeneration, enhanced apoptosis, and low regeneration capacity of neurons). IL-1 $\beta$ exacerbates neural cell death and upregulates NMDA receptors (93), thus impairing hippocampal neurogenesis. Also, IL-1 $\beta$ decreases the hippocampal expression of a survival factor-neurotrophin tyrosine kinase and induces the production of free radicals and degradative MMP in astrocytes and endothelial cells. Other inflammatory cytokines, e.g., IL-6, seem to have a dual role in neuronal homeostasis: overexpression of IL-6 in mice causes neurodegeneration (94). Grønhøj et al (95) investigated the effects of intravenously administered IL-6 in parallel with the soluble IL-6 receptor in mice with permanent MCAO. They found that IL-6 alone improved motor and sensory functions and did not affect the size of infarction in wild-type C57BL/6 animals, but it reduced infarct size in IL- $6^{-/}$counterparts.

Moreover, co-administration of IL-6 and IL-6R increased infarct size $24 \mathrm{~h}$ after permanent MCAO, worsened the motor functions, and triggered the invasion of polymorphonuclear leucocytes. Increased expression of IL- 6 and IL-6R has been detected in the surviving cortical neurons $72 \mathrm{~h}$ after permanent MCAO (95). A putative pathway of IL-6 trans-signaling to promote depression is the downregulation of methyl CpG-binding protein 2 and local melatonin production in macrophage/microglia (96). TNFa is involved in the perpetuation of ischemic brain damage by inducing apoptosis via caspase-mediated pathways and glutaminase upregulation together with inhibition of glutamine transporter activity (97). IFN $\gamma$ is a potent inducer of indoleamine 2,3-dioxygenase (IDO), with the generation of multiple neurodegenerative effects through tryptophan catabolic products (6). In acute human ischemic stroke, plasma concentrations of IL-6, IL- 8 and TNF $\alpha$ were significantly higher at $72 \mathrm{~h}$, but reduced quantities of IL-1 $\beta$, IL-6, IL-8 and TNF $\alpha$ mRNA were detected in peripheral leukocytes, and the only variation of IL-6 was correlated with the severity and outcome of stroke (98). IL-1 and TNF $\alpha$ act synergistically on the stimulation of NF- $\kappa \mathrm{B}$ (99). Pro-inflammatory cytokines act via mitogen-activated protein kinase targets, among which the ERK1/2 kinase pathway is implicated in neuronal functions, such as plasticity, maintenance, survival, and immune responses of neurons $(100,101)$.

It has been demonstrated in an endothelin-induced focal cerebral ischemia model, that peripheral administration of TNF $\alpha$ can induce IL- 4 and IL-10 and suppress IFN $\gamma$ in the brain if applied on the innate immune system training background (repeated administration of LPS) (102). This striking result indicates that cytokine production in resident microglia is contextual and should always be interpreted in conjunction with external inductors and inhibitors. Apart from this, prolonged elevation of pro-inflammatory mediators determines neurodegeneration and neuronal loss, and probably preconditions PSD.

The pathogenic role of proinflammatory cytokines in post-stroke neuroprogression is synthesized in Fig. 1.

$T N F \alpha$ and IFN $\gamma$ interfere with glutamatergic signaling in post-stroke depression. The association between elevated concentrations of pro-inflammatory cytokines and major depression has often been proposed $(103,104)$. A meta-analysis found that blood concentrations of IL-6, TNF $\alpha$ and IL-2R are significantly higher in major depressive disorder patients than in healthy controls, but the analysis did not evaluate the relationship between these cytokines and the severity of depression (105). An early study that linked high IL-6, TNFa and IFN $\gamma$ levels with post-stroke depression (106) found a 12-fold increase of IL-6 and a 40-fold increase of IFN $\gamma$ in stroke patients who developed depression in a 12-month follow-up but had no symptoms at the time of first hospital admission. The association of IL- 6 and IFN $\gamma$ has an essential functional consequence, since these cytokines both upregulate the tryptophan-degrading enzyme IDO, thus increasing the metabolization of tryptophan and reducing the synthesis of serotonin (107). Neurons, microglia and infiltrating monocytes all express IDO, but their catabolic end products are different; neurons metabolize tryptophan to 5-HT, and astrocytes produce kynurenic acid, whereas the main end-product in microglia is quinolinic acid, which provokes glutamate release (108) and suspends glutamate uptake, resulting in increased quantities of extrasynaptic glutamate (109). Quinolinic acid is an NMDA receptor agonist that enhances the extrasynaptic NMDA receptor response and decreases BDNF production (7).

Moreover, quinolinic acid increases nicotinamide-adeninedinucleotide $\left(\mathrm{NAD}^{+}\right)$, induces sirtuin-1 and -3 , and finally, inflicts mitochondrial dysfunction (96). Interestingly, the dispersion of NMDA receptor and quinolinic acid-producing microglia cells overlap in the subgenual and dorsal anterior cingulate cortex (7). In summary, pro-inflammatory cytokines inhibit the 5-HT synthesis and its neurotrophic effects in 


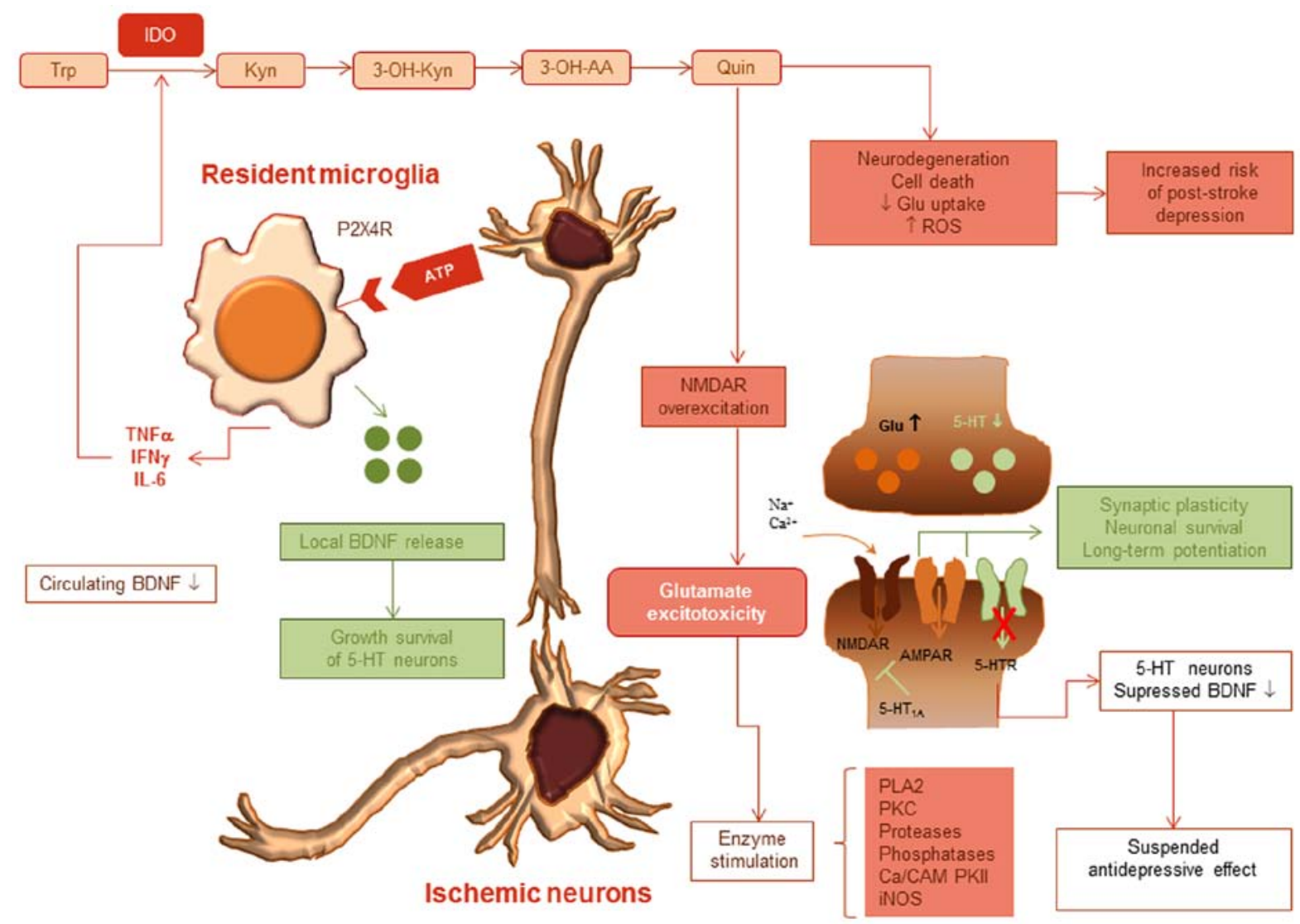

Figure 2. Ischemic neuron-glia cell interactions alter tryptophane metabolism and induce glutamate excitotoxicity. ATP-triggered resident microglia releases pro-inflammatory cytokines IL-6, IFN $\gamma$ and TNF $\alpha$. These activate indoleamine 2,3-dioxygenase, degrading tryptophan to kynurenine, 3-OH kynurenine, 3-OH anthranilic acid and finally, quinolinic acid. Increased quinolinic acid in the region of injury provokes neurodegeneration, apoptosis, whereas reactive oxygen species production excites NMDAR, and mediates glutamate excitotoxicity, increasing the risk of post-stroke depression. Microglia also secrete BDNF, which shows high concentration in the ischemic core, probably in a reparative endeavor, but is downregulated in the systemic circulation. AMPAR and 5-HT receptors are suppressed, decreasing synaptic plasticity and neuronal survival. IL, interleukin; TNF $\alpha$, tumor necrosis factor $\alpha$; IFN $\gamma$, interferon $\gamma$; BDNF, brain-derived neurotrophic factor.

the brain while upregulating tryptophan metabolites, among which quinolinic acid mainly generates harmful effects: Hippocampal cell death and neuronal degeneration; excitotoxicity via the NMDA receptors; inhibition of glutamate uptake; increased production of reactive oxygen species; and mitochondrial dysfunction $(7,110)$. Individuals who have acute depressive episodes have higher quinolinic acid concentrations in their blood and cerebrospinal fluid (111). On the other hand, BDNF and 5-HT are ambassadors of synaptic plasticity and neuronal survival, and they positively influence each other: BDNF stimulates the growth and survival of 5-HT neurons, whereas 5-HT facilitates the expression of BDNF in the ischemic brain. The selective 5-HT1A agonist 8-hydroxy-2-(di- $n$-propylamino) tetralin suppresses the phosphorylation of NMDA receptor subunit NR1 at Ser897 and thus prevents excessive NMDA receptor activation (112).

The alteration of tryptophan metabolism and the regulatory pathways of glutamate excitotoxicity are shown in Fig. 2.

The role of other well-known inflammatory cytokines in PSD is not clear. The link between IL-17 and depression is contradictory: Davami et al (113) found no relationship of depression with serum IL-17, whereas Liu et al (105) found elevated levels, but only in depressed patients with rheumatoid arthritis as a co-morbidity. Th17 cells and retinoic acid receptor-related orphan receptors, a transcription factor crucial for the development of depression, can increase susceptibility to the disorder (114). IL-17-expressing lymphocytes are elevated as early as one hour after the ischemic trigger in transient MCAO (115). A study that profiled the IL-17 mRNA elevation curve in cerebral ischemia found an elevation after one day, a peak at day 3 , and high protein concentrations persisting at day 6 (116).

Osteoprotegerin and RANKL modulate the post-ischemic inflammatory response and the pro-resolving microglia/macrophage activation. In a hypoxia-ischemia cellular model, oxygen and glucose deprivation stimulated TNF $\alpha$ - and IFN $\gamma$-mediated cytotoxicity on neurons and oligodendrocytes. TNF also exerted toxicity on neurons, but this effect was modulated through its decoy receptors, osteoprotegerin (OPG), and TNF-related apoptosis-inducing ligand R2 (117). OPG is also a decoy receptor for the receptor activator of nuclear $\kappa \mathrm{B}$ ligand (RANKL), making part of the regulatory OPG/RANKL/RANK triad and is significantly increased in acute stroke and other atherosclerotic manifestations of atherosclerotic polyvascular disease $(118,119)$. In wild-type mice, OPG, RANKL and RANK, all are overexpressed at the ischemic border region. In $\mathrm{OPG}^{-/-}$mice, the RANKL/RANK signaling reduces cerebral edema and infarction volume, but the effect is the opposite when these 
signals are repressed. Baseline mRNA levels of IL-6, TNF $\alpha$, IL-1 $\beta$, monocyte chemoattractant protein-1 MCP-1, iNOS and Arg1, obtained from neuronal-glial mixed cultures, are low in $\mathrm{OPG}^{-/}$mice (120). When these animals suffered brain infarction, IL-6, TNF $\alpha$, IL-1 $\beta$, MCP-1, and iNOS concentrations remained lower, and Arg1 values were higher than in wild-type counterparts. Thus, via Arg1, RANKL probably is a positive regulator of M2 type resolution-promoting macrophages. In wild-type controls, RANKL also reduced IL-1 $\beta$ and MCP-1 but did not affect the expression of iNOS and Arg1. A possible explanation of this finding is a more robust alternative activation of macrophages in the absence of OPG (120). Table I summarizes evidence suggesting the specific microenvironments and M2 type differentiations with roles in post-stroke depression.

\section{Experimental evidence for pharmacological checkpoints of inflammation}

MMPs are critical regulators of neuronal death/survival and tissue regeneration. The overexpression of MMP-9 was documented in the ischemic brain, and a causal relationship with the disruption of the blood-brain barrier and hemorrhagic transformation has been proposed (121). In a global cerebral ischemia model, the cyclooxygenase 2 inhibitor robenacoxib, when administered alone, enhanced neuronal death rather than protecting the cells (122); however, when administered together with salubrinal, an endoplasmatic reticulum stress inhibitor, robenacoxib diminished neuronal loss and glial activation. 2-Hydroxyarachidonic acid, a cyclooxygenase inhibitor, acts suspending also on phospholipase A2, a mediator of membrane phospholipid cleavage, and decreases infarct volume in rats (123). In a carotid embolism stroke model, atorvastatin and meloxicam reduced the inflammatory process, neurodegeneration, and morphological changes specific for astrocytes and microglia (124). Llorente et al (125) examined whether meloxicam protects against glutamatergic excitotoxicity in cultures of organotypic hippocampal slices. They found decreased mRNA synthesis of glutamatergic transporters VGLUT1, VGLUT2, GLAST-1A, GLT-1 and EAAC-1 and some receptor subunits, but not of membrane transporters. They concluded that the drug could selectively modulate the expression of the glutamatergic signaling system components along the NMDA: AMPA receptor stoichiometry and repress glutamate excitotoxicity, leading to neuronal death. Meloxicam represses low-grade inflammation, even in non-vascularized tissues (126), and has a dual beneficial effect on extracellular matrix repair. Through its anti-fibrotic effect, downregulates the hydroxyproline production and collagen deposition, and it is angiostatic and anti-oxidant through stimulation of glutathione peroxidase, catalase, superoxide dismutase, and decrease of lipid peroxidation and myeloperoxidase activity $(127,128)$. In a model of kidney interstitial fibrosis, meloxicam inhibited type IV collagen mRNA together with the heat shock protein hsp47, which are indispensable for collagen synthesis, ERK and JNK kinases (129). The anti-fibrotic and anti-collagenolytic effects were also evident in rat liver and cartilage, where meloxicam downregulated collagen type I and II degradation, smooth muscle actin $\alpha$, hydroxyproline, and, interestingly, TGF $\beta$ along with tissue inhibitor of MMP-1 (TIMP-1) $(128,130)$. Linalool, a monoterpene, was effective in treating glutamate excitotoxicity by improving the altered profiles of mono-/polyunsaturated fatty acids in membrane phospholipids, reducing microgliosis and cyclooxygenase-2 (Cox-2) expression, and by improving motor and cognitive performances of ischemic Wistar rats (131). Our recent research $(132,133)$ revealed that fish oil with high eicosapentaenoic acid content triggered an M2/M1 macrophage phenotype shift in the spleen and bone marrow of rats exposed to transient MCAO. C-phycocyanin and phycocyanobilin, the chromoproteins of cyanobacteria Spirulina platensis, exert beneficial effects in ischemic animal models. Besides inhibition of Cox-2 and upregulation of BDNF expression, they limit the proinflammatory mediators IL-17A, IL- $1 \beta$ and TNF- $\alpha$, promote the differentiation of oligodendrocytes, and support the repair of ischemic demyelination (134).

CR2-Crry, an overall inhibitor of complement pathways, and $\mathrm{CR} 2-\mathrm{fH}$, an inhibitor of the alternative pathway, reduce microglia/macrophage activation, infarct size, and improve neurological scores in mice in the acute post-stroke phase. In the subacute phase, only the alternative pathway inhibitor improved neurological deficit, neurogenesis, and neuronal migration and also downregulated neutrophil infiltration, IL-1 $\alpha$, and a series of matrix metalloproteinases; protection against cell death was especially evident in the hippocampus (135). Cox-2 inhibition with rofecoxib increases 5-HT levels in the prefrontal and parietal cortex. Another Cox-2 inhibitor, celecoxib, efficiently decreases the hypothalamus proinflammatory cytokine levels and the behavioral impairment in experimental models (136). Celecoxib, combined with antidepressants, such as fluoxetine or sertraline, exerts a more substantial anti-depressive effect than the antidepressant alone $(137,138)$. Anti-TNF therapy is effective in reducing neuroinflammation (139). Suppression of inflammatory signs was also observed in HIV-1 transgenic adolescent rats, with signs of depression and high expression of MCP-1 in the hippocampus; oral meloxicam treatment reduces MCP-1 but does not reverse the depressive behavior (140). In an exciting new approach, Liu et al (141) applied 50\% argon $/ 50 \%$ oxygen on Wistar rats supposed to tMCAO, $3 \mathrm{~h}$ after starting the procedure, and $1 \mathrm{~h}$ after reperfusion. They observed the gas mixture improved significantly a 6-point neuroscore, neuronal survival (measured as the intensity of NeuN expression), and a robust polarization of macrophages to the $\mathrm{Iba}-1^{+} / \mathrm{Arg} 1^{+} \mathrm{M} 2$ form.

\section{Discussion}

Post-stroke depression occurs in about one-third of stroke patients; depression decreases the quality of life, predicts the recurrence of stroke, and increases the mortality rate. In PSD, many studies have reported disruption of frontal cortico-limbic circuits, although this functional dysequilibrium is probably a consequence of the post-stroke immune response and neuroinflammation.

Brain-derived neurotrophic factor, synthesized in neurons, astrocytes, and microglia, is essential for neuronal survival, plasticity and may play an essential role in the recovery phase of stroke. Antidepressant treatments restore BDNF levels, which, interestingly, also are increased in the ischemic core of rats with experimental stroke. The release of BDNF is tightly 
Table I. Suggesting evidence for the role of pro-resolving, M2 type microglia/macrophage in post-stroke depression.

$\begin{array}{lccc}\begin{array}{l}\text { Experimental } \\ \text { model }\end{array} & \begin{array}{c}\text { Cytokine/mediator } \\ \text { environment }\end{array} & \text { Host } & \text { Effect }\end{array}$

\begin{tabular}{|c|c|c|}
\hline $\begin{array}{l}\text { Middle cerebral } \\
\text { artery occlusion }\end{array}$ & Anti-CD49d antibodies & Perforin $^{-/-}$mice \\
\hline $\begin{array}{l}\text { Transient middle } \\
\text { cerebral artery } \\
\text { occlusion }\end{array}$ & $\begin{array}{l}\text { OPG deletion } \\
\text { RANKL? }\end{array}$ & $\begin{array}{l}\mathrm{OPG}^{-/} \text {mice and } \\
\text { wild-type mice }\end{array}$ \\
\hline
\end{tabular}

Anti-CD49d therapy depleted infiltrating

lymphocytes, Iba- $1^{+}$microglia, and IFN $\gamma$ secretion

Baseline levels of IL-6, TNF $\alpha$, IL-1 $\beta$,

MCP-1, iNOS and Arg1 low

After brain infarction, IL-6, TNF $\alpha, \mathrm{IL}-1 \beta$,

MCP-1 remained low, $\uparrow$ Arg1 expression

in $\mathrm{OPG}^{-/-}$animals RANKL positive

regulator of M2 type differentiation

Predicted effects: Impaired

axon guidance and extension,

synaptic transmission,

learning and memory

CD200R is upregulated on microglia,

but CD200 signaling fades

in ischemic neuronal injury

CD200R signaling via CREB-C/EBP- $\beta$

promotes $A r g 1^{+}$microglia differentiation,

silent state, anti-inflammatory phenotype

Upregulation TGF $\beta$, downregulation of IL-1 $\beta$,

IL-6 and G-CSF

Cerebral ischemia

IL-4

Mice

Cerebral ischemia

IL-4, IL-10, TGF $\beta$

Mice

Transient middle

cerebral artery

occlusion/

permanent distal

middle cerebral

artery occlusion

$$
\text { IL-4 }
$$

C57BL IL-4 ${ }^{-/-}$

mice

Amplification of M2 type differentiation,

but no attenuation of the functional

outcome and lesion size

M2 type myeloid cells present

intense phagocytosis and increased

secretion of IL-4, IL-10, TGF $\beta$

Reversal of M1 type, differentiation

by IL-4 administration IL-4

beneficial in the long-term recovery
Focal cerebral

ischemia

Middle cerebral

artery occlusion

Middle cerebral

artery occlusion

miRNA-124
Bone marrow-
derived monocyte
transplantation

Anti-MCP-1

Intracerebral

hemorrhage

IL-10

CD28SA
C57BL/6

Chimeric

CX3CR1-GFP

and whole body-irradiated C57BL mice

Chimeric CX3CR1GFP and whole body-irradiated C57BL mice

C57BL/6

male mice
Increased number of $\mathrm{Arg} 1^{+}$microglia/ macrophage, increased neuronal survival Ly $6 \mathrm{C}^{\text {low }}, \mathrm{BDNF}^{+}$bone-marrow-derived

Liesz et al (55)

Shimamura et al

macrophages in the ischemic lesion at 14 days

High TGF $\beta$, CXCL13 and CD163

expression in hemicerebral tissue homogenate

Brites and

Fernandes (88)

Szepesi et al

Hayakawa et al

Selective monocyte depletion with anti-MCP1 antibody resulted in impaired functional tests in the late-stage recovery

Xia et al (66) (at 7 days post-stroke)

IL-10-treated Tregs support M2

microglia/macrophage differentiation through glycogen synthase kinase $3 \beta$ and phosphatase and tensin homolog

Boosting Tregs with CD28 agonist enhances

M2 type differentiation, TGF $\beta$, and IL-10 producer cells

HMGB 1 and PRX are internalized

in vitro through MSR-1

Taj et al (67)

Wattananit et al

MSR-1 and Marco deficiency impairs

clearance of DAMPs, exacerbates

inflammation and neuronal injury in infiltrating

myeloid cells
Mice

Murine ischemic

stroke 
linked to the activation of ATP-sensitive purinergic P2X4R receptors, which are dense on resident microglia and infiltrating macrophages. The importance of purinergic signaling in stroke and PSD is reflected by the fact that global knock-out of P2X4R reduces infarct size, whereas myeloid-specific deletion causes anhedonia and depressive behavior in the late-stage.

Danger signals released in the acute phase of stroke transmit glutamate excitotoxicity via NMDA receptors. In the acute phase, ischemia turns on inflammatory mechanisms: neutrophils and, later, monocytes invade the lesion due to chemotactic signals, such as CX3CL1 and CCL2. Pro-inflammatory cytokines, especially IL-1 $\beta$, TNF $\alpha$, IL-6 and IFN $\gamma$, elicit neuronal degeneration, apoptosis, and low regeneration capacity, and interfere with tryptophan catabolism. The main degradation product of tryptophan in microglia is quinolinic acid, an NMDA receptor agonist and 5-HT antagonist that exerts glutamate excitotoxicity, suppressing glutamate uptake, reducing synaptic plasticity and neuronal survival. Experimental studies have revealed that the anti-inflammatory cytokines IL-4, IL-10 and TGF $\beta$ are protective in stroke by limiting the lesions and determining macrophages to M2 type differentiation. In the chronic recovery phase, resident microglia and macrophages probably have a central role in modulating tissue repair, BDNF signaling, 5-HT neurotransmission and thus the development of post-stroke depression. However, according to recent observations, these cells differ in their behavior. In essence, resident microglia in some circumstances seem to be silent, other times pro-inflammatory, whereas bone-marrow-derived infiltrating monocytes at the late recovery stage are anti-inflammatory and may play a critical role in the late-phase tissue repair and neurological rehabilitation. Some ambiguity persists in the nomenclature of pro-resolving macrophages, and there is a clear need for the accurate description of their stimuli and extended phenotype. Moreover, since it has been documented that repeated peripheral pro-inflammatory stimuli can train microglia and downregulate their cytokine expression, future studies dedicated to the mapping of brain-repair factors need to address in parallel both the local and peripheric immune response.

\section{Acknowledgements}

Not applicable.

\section{Funding}

This study was supported by an internal research grant of the 'Emil Palade' University of Medicine, Pharmacy, Science and Technology of Targu Mures, Romania (no. 17803/1/22.12.2015) and partially funded by the Studium-Prospero Foundation, Romania (contract no. 1547/18.12.2015).

\section{Availability of data and materials}

Not applicable.

\section{Authors' contributions}

EEN conceived the study, acquired the data and wrote the manuscript. AF and JAS acquired the data and revised the manuscript critically for important intellectual content. EH was also involved in the conception of the study, was responsible for the acquisition of funding and the critical revision of the manuscript. All authors read and approved the final manuscript.

\section{Ethics approval and consent to participate}

Not applicable.

\section{Patient consent for publication}

Not applicable.

\section{Competing interests}

The authors declare that they have no competing interests.

\section{References}

1. Staub F and Bogousslavsky J: Post-stroke depression or fatigue. Eur Neurol 45: 3-5, 2001.

2. Gaete JM and Bogousslavsky J: Post-stroke depression. Expert Rev Neurother 8: 75-92, 2008.

3. Paolucci S, Iosa M, Coiro P, Venturiero V, Savo A, De Angelis D and Morone G: Post-stroke depression increases disability more than $15 \%$ in ischemic stroke survivors: A case-control study. Front Neurol 10: 926, 2019.

4. Ayerbe L, Ayis S, Wolfe CD and Rudd AG: Natural history, predictors and outcomes of depression after stroke: Systematic review and meta-analysis. Br J Psychiatry 202: 14-21, 2013.

5. Sibolt G, Curtze S, Melkas S, Pohjasvaara T, Kaste M, Karhunen PJ, Oksala NK, Vataja R and Erkinjuntti T: Post-stroke depression and depression-executive dysfunction syndrome are associated with recurrence of ischaemic stroke. Cerebrovasc Dis 36: 336-343, 2013.

6. Leonard B and Maes M: Mechanistic explanations how cell-mediated immune activation, inflammation and oxidative and nitrosative stress pathways and their sequels and concomitants play a role in the pathophysiology of unipolar depression. Neurosci Biobehav Rev 36: 764-785, 2012.

7. Woelfer M, Kasties V, Kahlfuss S and Walter M: The role of depressive subtypes within the neuroinflammation hypothesis of major depressive disorder. Neuroscience 403: 93-110, 2019.

8. Maes M: A review on the acute phase response in major depression. Rev Neurosci 4: 407-416, 1993.

9. Murray PJ, Allen JE, Biswas SK, Fisher EA, Gilroy DW, Goerdt S, Gordon S, Hamilton JA, Ivashkiv LB, Lawrence T, et al: Macrophage activation and polarization: Nomenclature and experimental guidelines. Immunity 41: 14-20, 2014.

10. Robinson RG and Jorge RE: Post-stroke depression: A review. Am J Psychiatry 173: 221-231, 2016.

11. Folstein MF, Maiberger R and McHugh PR: Mood disorder as a specific complication of stroke. J Neurol Neurosurg Psychiatry 40: 1018-1020, 1977.

12. Narushima K, Kosier JT and Robinson RG: A reappraisal of poststroke depression, intra- and inter-hemispheric lesion location using meta-analysis. J Neuropsychiatry Clin Neurosci 15: 422-430, 2003.

13. Spalletta G, Bossù $\mathrm{P}$, Ciaramella $\mathrm{A}$, Bria $\mathrm{P}$, Caltagirone $\mathrm{C}$ and Robinson RG: The etiology of poststroke depression: A review of the literature and a new hypothesis involving inflammatory cytokines. Mol Psychiatry 11: 984-991, 2006.

14. Carson AJ, MacHale S, Allen K, Lawrie SM, Dennis M, House A and Sharpe M: Depression after stroke and lesion location: A systematic review. Lancet 356: 122-126, 2000.

15. Kutlubaev MA and Hackett ML: Part II: predictors of depression after stroke and impact of depression on stroke outcome: an updated systematic review of observational studies. Int $\mathbf{J}$ Stroke 9: 1026-1036, 2014.

16. MacHale SM, O'Rourke SJ, Wardlaw JM and Dennis MS: Depression and its relation to lesion location after stroke. J Neurol Neurosurg Psychiatry 64: 371-374, 1998.

17. Nys GM, van Zandvoort MJ, van der Worp HB, de Haan EH, de Kort PL and Kappelle LJ: Early depressive symptoms after stroke: Neuropsychological correlates and lesion characteristics. J Neurol Sci 228: 27-33, 2005. 
18. Terroni L, Amaro E Jr, Iosifescu DV, Tinone G, Sato JR, Leite CC, Sobreiro MF, Lucia MC, Scaff M and Fráguas R: Stroke lesion in cortical neural circuits and post-stroke incidence of major depressive episode: A 4-month prospective study. World J Biol Psychiatry 12: 539-548, 2011.

19. Morris PL, Robinson RG, de Carvalho ML, Albert P, Wells JC, Samuels JF, Eden-Fetzer D and Price TR: Lesion characteristics and depressed mood in the stroke data bank study. J Neuropsychiatry Clin Neurosci 8: 153-159, 1996.

20. Kim NY, Lee SC, Shin JC, Park JE and Kim YW: Voxel-based lesion symptom mapping analysis of depressive mood in patients with isolated cerebellar stroke: A pilot study. Neuroimage Clin 13: 39-45, 2017.

21. Nishiyama Y, Komaba Y, Ueda M, Nagayama H, Amemiya S and Katayama Y: Early depressive symptoms after ischemic stroke are associated with a left lenticulocapsular area lesion. J Stroke Cerebrovasc Dis 19: 184-189, 2010.

22. Zhang T, Jing X, Zhao X, Wang C, Liu Z, Zhou Y, Wang Y and Wang Y: A prospective cohort study of lesion location and its relation to post-stroke depression among Chinese patients. J Affect Disord 136: e83-e87, 2012.

23. Gozzi SA, Wood AG, Chen J, Vaddadi K and Phan TG: Imaging predictors of poststroke depression: Methodological factors in voxel-based analysis. BMJ Open 4: e004948, 2014.

24. Grajny K, Pyata H, Spiegel K, Lacey EH, Xing S, Brophy C and Turkeltaub PE: depression symptoms in chronic left hemisphere stroke are related to dorsolateral prefrontal cortex damage. J Neuropsychiatry Clin Neurosci 28: 292-298, 2016.

25. Shi YZ, Xiang YT, Yang Y, Zhang N, Wang S, Ungvari GS, Chiu HF, Tang WK, Wang YL, Zhao XQ, et al: Depression after minor stroke: The association with disability and quality of life - a 1-year follow-up study. Int J Geriatr Psychiatry 31: 421-427, 2016.

26. Yu $\mathrm{H}$ and Chen $\mathrm{ZY}$ : The role of BDNF in depression on the basis of its location in the neural circuitry. Acta Pharmacol Sin 32: 3-11, 2011.

27. Elkabes S, DiCicco-Bloom EM and Black IB: Brain microglia/macrophages express neurotrophins that selectively regulate microglial proliferation and function. J Neurosci 16 : 2508-2521, 1996.

28. Knott C, Stern G, Kingsbury A, Welcher AA and Wilkin GP: Elevated glial brain-derived neurotrophic factor in Parkinson's diseased nigra. Parkinsonism Relat Disord 8: 329-341, 2002.

29. Stadelmann C, Kerschensteiner M, Misgeld T, Brück W, Hohlfeld R and Lassmann H: BDNF and gp145trkB in multiple sclerosis brain lesions: Neuroprotective interactions between immune and neuronal cells? Brain 125: 75-85, 2002.

30. Trang T, Beggs S, Wan X and Salter MW: P2X4-receptor-mediated synthesis and release of brain-derived neurotrophic factor in microglia is dependent on calcium and p38-mitogen-activated protein kinase activation. J Neurosci 29: 3518-3528, 2009.

31. Song X, Zhou B, Zhang P, Lei D, Wang Y, Yao G, Hayashi T, Xia M, Tashiro S, Onodera S, et al: Protective effect of silibinin on learning and memory impairment in LPS-treated rats via ROS-BDNF-TrkB pathway. Neurochem Res 41: 1662-1672, 2016.

32. Smith MA, Makino S, Kvetnansky R and Post RM: Stress and glucocorticoids affect the expression of brain-derived neurotrophic factor and neurotrophin-3 mRNAs in the hippocampus J Neurosci 15: 1768-1777, 1995.

33. Lang UE, Hellweg R, Kalus P, Bajbouj M, Lenzen KP, Sander T, Kunz D and Gallinat J: Association of a functional BDNF polymorphism and anxiety-related personality traits. Psychopharmacology (Berl) 180: 95-99, 2005.

34. Monteggia LM, Luikart B, Barrot M, Theobold D, Malkovska I, Nef S, Parada LF and Nestler EJ: Brain-derived neurotrophic factor conditional knockouts show gender differences in depression-related behaviors. Biol Psychiatry 61: 187-197, 2007.

35. Duman RS: Pathophysiology of depression: The concept of synaptic plasticity. Eur Psychiatry 17 (Suppl 3): 306-310, 2002.

36. Fujimura H, Altar CA, Chen R, Nakamura T, Nakahashi T, Kambayashi J, Sun B and Tandon NN: Brain-derived neurotrophic factor is stored in human platelets and released by agonist stimulation. Thromb Haemost 87: 728-734, 2002.

37. Lee BH and Kim YK: The roles of BDNF in the pathophysiology of major depression and in antidepressant treatment. Psychiatry Investig 7: 231-235, 2010

38. Pan W, Banks WA, Fasold MB, Bluth J and Kastin AJ: Transport of brain-derived neurotrophic factor across the blood-brain barrier. Neuropharmacology 37: 1553-1561, 1998.
39. Gonul AS, Akdeniz F, Taneli F, Donat O, Eker C and Vahip S: Effect of treatment on serum brain-derived neurotrophic factor levels in depressed patients. Eur Arch Psychiatry Clin Neurosci 255: 381-386, 2005.

40. Chaudhury D, Liu H and Han MH: Neuronal correlates of depression. Cell Mol Life Sci 72: 4825-4848, 2015.

41. Jin Y, Sun LH, Yang W, Cui RJ and Xu SB: The role of BDNF in the neuroimmune axis regulation of mood disorders. Front Neurol 10: 515, 2019.

42. Jiang MQ, Zhao YY, Cao W, Wei ZZ, Gu X, Wei L and Yu SP: Long-term survival and regeneration of neuronal and vasculature cells inside the core region after ischemic stroke in adult mice. Brain Pathol 27: 480-498, 2017.

43. North RA and Jarvis MF: P2X receptors as drug targets. Mol Pharmacol 83: 759-769, 2013

44. Vázquez-Villoldo N, Domercq M, Martín A, Llop J, Gómez-Vallejo V and Matute C: P2X4 receptors control the fate and survival of activated microglia. Glia 62: 171-184,2014.

45. Verma R, Cronin CG, Hudobenko J, Venna VR, McCullough LD and Liang BT: Deletion of the P2X4 receptor is neuroprotective acutely, but induces a depressive phenotype during recovery from ischemic stroke. Brain Behav Immun 66: 302-312, 2017.

46. Bravo-Alegria J, McCullough LD and Liu F: Sex differences in stroke across the lifespan: The role of T lymphocytes. Neurochem Int 107: 127-137, 2017.

47. Xu S, Lu J, Shao A, Zhang JH and Zhang J: Glial cells: Role of the immune response in ischemic stroke. Front Immunol 11: 294, 2020.

48. Zera KA and Buckwalter MS: The Local and peripheral immune responses to stroke: Implications for therapeutic development. Neurotherapeutics: Mar 19, 2020 (Epub ahead of print). doi: 10.1007/s13311-020-00844-3.

49. Zamanian JL, Xu L, Foo LC, Nouri N, Zhou L, Giffard RG and Barres BA: Genomic analysis of reactive astrogliosis. J Neurosci 32: 6391-6410, 2012.

50. Zhao X, Wang H, Sun G, Zhang J, Edwards NJ and Aronowski J: Neuronal interleukin-4 as a modulator of microglial pathways and ischemic brain damage. J Neurosci 35: 11281-11291, 2015.

51. Lee GA, Lin TN, Chen CY, Mau SY, Huang WZ, Kao YC, Ma RY and Liao NS: Interleukin 15 blockade protects the brain from cerebral ischemia-reperfusion injury. Brain Behav Immun 73: 562-570, 2018

52. Dolati S, Ahmadi M, Khalili M, Taheraghdam AA, SiahmansouriH,BabalooZ,Aghebati-Maleki L, Jadidi-NiaraghF, Younesi V and Yousefi M: Peripheral Th17/Treg imbalance in elderly patients with ischemic stroke. Neurol Sci 39: 647-654, 2018.

53. Santamaría-Cadavid M,Rodríguez-Castro E,Rodríguez-Yáñez M, Arias-Rivas S, López-Dequidt I, Pérez-Mato M, RodríguezPérez M, López-Loureiro I, Hervella P, Campos F, et al: Regulatory $\mathrm{T}$ cells participate in the recovery of ischemic stroke patients. BMC Neurol 20: 68, 2020.

54. Stubbe T, Ebner F, Richter D, Engel O, Klehmet J, Royl G, Meisel A, Nitsch R, Meisel C and Brandt C: Regulatory T cells accumulate and proliferate in the ischemic hemisphere for up to 30 days after MCAO. J Cereb Blood Flow Metab 33: 37-47, 2013

55. Liesz A, Zhou W, Mracskó É, Karcher S, Bauer H, Schwarting S, Sun L, Bruder D, Stegemann S, Cerwenka A, et al: Inhibition of lymphocyte trafficking shields the brain against deleterious neuroinflammation after stroke. Brain 134: 704-720, 2011.

56. Doyle KP, Quach LN, Solé M, Axtell RC, Nguyen TV, Soler-Llavina GJ, Jurado S, Han J, Steinman L, Longo FM, et al: B-lymphocyte-mediated delayed cognitive impairment following stroke. J Neurosci 35: 2133-2145, 2015.

57. Rayasam A, Hsu M, Hernández G, Kijak J, Lindstedt A, Gerhart C, Sandor M and Fabry Z: Contrasting roles of immune cells in tissue injury and repair in stroke: The dark and bright side of immunity in the brain. Neurochem Int 107: 104-116, 2017.

58. Nakamura $\mathrm{K}$ and Shichita T: Cellular and molecular mechanisms of sterile inflammation in ischaemic stroke. J Biochem 165: 459-464, 2019

59. Szepesi Z, Manouchehrian O, Bachiller S and Deierborg T: Bidirectional microglia-neuron communication in health and disease. Front Cell Neurosci 12: 323, 2018.

60. Sharp FR, Zhan X and Liu DZ: Heat shock proteins in the brain: Role of Hsp70, Hsp 27, and HO-1 (Hsp32) and their therapeutic potential. Transl Stroke Res 4: 685-692, 2013.

61. Nitti M, Piras S, Brondolo L, Marinari UM, Pronzato MA and Furfaro AL: Heme Oxygenase 1 in the nervous system: Does it favor neuronal cell survival or induce neurodegeneration? Int J Mol Sci 19: E2260, 2018 
62. Hermann DM, Kleinschnitz C and Gunzer M: Role of polymorphonuclear neutrophils in the reperfused ischemic brain: Insights from cell-type-specific immunodepletion and fluorescence microscopy studies. Ther Adv Neurol Disord 11: 1756286418798607, 2018.

63. Bennett ML, Bennett FC, Liddelow SA, Ajami B, Zamanian JL, Fernhoff NB, Mulinyawe SB, Bohlen CJ, Adil A, Tucker A, et al: New tools for studying microglia in the mouse and human CNS. Proc Natl Acad Sci USA 113: E1738-E1746, 2016.

64. Zarruk JG, Greenhalgh AD and David S: Microglia and macrophages differ in their inflammatory profile after permanent brain ischemia. Exp Neurol 301: 120-132, 2018.

65. Shichita T, Ito M, Morita R, Komai K, Noguchi Y, Ooboshi H, Koshida R, Takahashi S, Kodama T and Yoshimura A: MAFB prevents excess inflammation after ischemic stroke by accelerating clearance of damage signals through MSR1. Nat Med 23: 723-732, 2017.

66. Xia CY, Zhang S, Gao Y, Wang ZZ and Chen NH: Selective modulation of microglia polarization to $\mathrm{M} 2$ phenotype for stroke treatment. Int Immunopharmacol 25: 377-382, 2015.

67. TajHS, Kho W, Riou A, Wiedermann D and Hoehn M: MiRNA-124 induces neuroprotection and functional improvement after focal cerebral ischemia. Biomaterials 91: 151-165, 2016.

68. Liu X, Liu J,Zhao S, Zhang H, Cai W, Cai M, Ji X, Leak RK, Gao Y, Chen J, et al: Interleukin-4 is essential for microglia/macrophage M2 polarization and long-term recovery after cerebral ischemia. Stroke 47: 498-504, 2016

69. Zhou K, Zhong Q, Wang YC, Xiong XY, Meng ZY, Zhao T, Zhu WY, Liao MF, Wu LR, Yang YR, et al: Regulatory T cells ameliorate intracerebral hemorrhage-induced inflammatory injury by modulating microglia/macrophage polarization through the IL-10/GSK3 $\beta /$ PTEN axis. J Cereb Blood Flow Metab 37: 967-979, 2017.

70. Titova EM, Ghosh N, Valadez ZG, Zhang JH, Bellinger DL and Obenaus A: The late phase of post-stroke neurorepair in aged rats is reflected by MRI-based measures. Neuroscience 283: 231-244, 2014.

71. Ongür D, Drevets WC and Price JL: Glial reduction in the subgenual prefrontal cortex in mood disorders. Proc Natl Acad Sci USA 95: 13290-13295, 1998.

72. Nimmerjahn A, Kirchhoff F and Helmchen F: Resting microglial cells are highly dynamic surveillants of brain parenchyma in vivo. Science 308: 1314-1318, 2005.

73. Smith RS: The macrophage theory of depression. Med Hypotheses 35: 298-306, 1991.

74. Dey A and Hankey Giblin PA: Insights into macrophage heterogeneity and cytokine-induced neuroinflammation in major Ddepressive disorder. Pharmaceuticals (Basel) 11: E64, 2018.

75. Xue J, Schmidt SV, Sander J, Draffehn A, Krebs W, Quester I, De Nardo D, Gohel TD, Emde M, Schmidleithner L, et al: Transcriptome-based network analysis reveals a spectrum model of human macrophage activation. Immunity 40: 274-288, 2014.

76. Orecchioni M, Ghosheh Y, Pramod AB and Ley K: Macrophage polarization: Different gene signatures in M1(LPS+) vs. classically and M2(LPS-) vs. alternatively activated macrophages. Front Immunol 10: 1084, 2019.

77. Ransohoff RM: A polarizing question: Do M1 and M2 microglia exist? Nat Neurosci 19: 987-991, 2016.

78. Eyo UB and Wu LJ: Bidirectional microglia-neuron communication in the healthy brain. Neural Plast 2013: 456857, 2013.

79. Hayakawa K, Wang X and Lo EH: CD200 increases alternatively activated macrophages through cAMP-response element binding protein-C/EBP-beta signaling. J Neurochem 136: 900-906, 2016.

80. Xu T, Pu S, Ni Y, Gao M, Li X and Zeng X: Elevated plasma macrophage migration inhibitor factor as a risk factor for the development of post-stroke depression in ischemic stroke. J Neuroimmunol 320: 58-63, 2018.

81. Yang DB, Yu WH, Dong XQ, Zhang ZY, Du Q, Zhu Q, Che ZH, Wang H, Shen YF and Jiang L: Serum macrophage migration inhibitory factor concentrations correlate with prognosis of traumatic brain injury. Clin Chim Acta 469: 99-104, 2017.

82. Leyton-Jaimes MF, Kahn J and Israelson A: Macrophage migration inhibitory factor: A multifaceted cytokine implicated in multiple neurological diseases. Exp Neurol 301: 83-91, 2018.

83. Chen H, Li X, Liu S, Gu L and Zhou X: MircroRNA-19a promotes vascular inflammation and foam cell formation by targeting HBP-1 in atherogenesis. Sci Rep 7: 12089, 2017.

84. Ritzel RM, Patel AR, Grenier JM, Crapser J, Verma R, Jellison ER and McCullough LD: Functional differences between microglia and monocytes after ischemic stroke. J Neuroinflammation 12: 106, 2015.
85. Meng HL, Li XX, Chen YT, Yu LJ, Zhang H, Lao JM, Zhang X and $\mathrm{Xu}$ Y: Neuronal soluble Fas ligand drives M1-Microglia polarization after cerebral ischemia. CNS Neurosci Ther 22: 771-781, 2016.

86. Wattananit S, Tornero D, Graubardt N, Memanishvili T, Monni E, Tatarishvili J, Miskinyte G, Ge R, Ahlenius H, Lindvall O, et al: Monocyte-derived macrophages contribute to spontaneous long-term functional recovery after stroke in mice. J Neurosci 36: 4182-4195, 2016

87. Horváth E, Huțanu A, Chiriac L, Dobreanu M, Orădan A and Nagy EE: Ischemic damage and early inflammatory infiltration are different in the core and penumbra lesions of rat brain after transient focal cerebral ischemia. J Neuroimmunol 324: 35-42, 2018.

88. Brites D and Fernandes A: Neuroinflammation and depression: Microglia activation, extracellular microvesicles and microRNA dysregulation. Front Cell Neurosci 9: 476, 2015.

89. Mezentsev A, Merks RM, O'Riordan E, Chen J, Mendelev N, Goligorsky MS and Brodsky SV: Endothelial microparticles affect angiogenesis in vitro: Role of oxidative stress. Am J Physiol Heart Circ Physiol 289: H1106-H1114, 2005.

90. Leroyer AS, Ebrahimian TG, Cochain C, Récalde A, Blanc-Brude O, Mees B, Vilar J, Tedgui A, Levy BI, Chimini G et al: Microparticles from ischemic muscle promotes postnatal vasculogenesis. Circulation 119: 2808-2817, 2009.

91. Garzetti L, Menon R, Finardi A, Bergami A, Sica A, Martino G, Comi G, Verderio C, Farina C and Furlan R: Activated macrophages release microvesicles containing polarized M1 or M2 mRNAs. J Leukoc Biol 95: 817-825, 2014.

92. Bianco F, Pravettoni E, Colombo A, Schenk U, Möller T, Matteoli M and Verderio C: Astrocyte-derived ATP induces vesicle shedding and IL-1 beta release from microglia. J Immunol 174: 7268-7277, 2005.

93. Viviani B, Gardoni F, Bartesaghi S, Corsini E, Facchi A, Galli CL, Di Luca M and Marinovich M: Interleukin-1 beta released by gp120 drives neural death through tyrosine phosphorylation and trafficking of NMDA receptors. J Biol Chem 281: 30212-30222, 2006.

94. Allan SM and Rothwell NJ: Inflammation in central nervous system injury. Philos Trans R Soc Lond B Biol Sci 358: 1669-1677, 2003.

95. Grønhøj MH, Clausen BH, Fenger CD, Lambertsen KL and Finsen B: Beneficial potential of intravenously administered IL-6 in improving outcome after murine experimental stroke. Brain Behav Immun 65: 296-311, 2017.

96. Anderson G, Kubera M, Duda W, Lasoń W, Berk M and Maes M: Increased IL- 6 trans-signaling in depression: Focus on the tryptophan catabolite pathway, melatonin and neuroprogression. Pharmacol Rep 65: 1647-1654, 2013.

97.Zou JY and Crews FT: TNF alpha potentiates glutamate neurotoxicity by inhibiting glutamate uptake in organotypic brain slice cultures: Neuroprotection by NF kappa B inhibition. Brain Res 1034: 11-24, 2005.

98. Zeng L, Wang Y, Liu J, Wang L, Weng S, Chen K, Domino EF and Yang GY: Pro-inflammatory cytokine network in peripheral inflammation response to cerebral ischemia. Neurosci Lett 548: 4-9, 2013.

99. Kaminska B: MAPK signalling pathways as molecular targets for anti-inflammatory therapy - from molecular mechanisms to therapeutic benefits. Biochim Biophys Acta 1754: 253-262, 2005.

100. Hetman M and Gozdz A: Role of extracellular signal regulated kinases 1 and 2 in neuronal survival. Eur J Biochem 271: 2050-2055, 2004.

101. Subramaniam S and Unsicker K: ERK and cell death: ERK1/2 in neuronal death. FEBS J 277: 22-29, 2010.

102. Wendeln AC, Degenhardt K, Kaurani L, Gertig M, Ulas T, Jain G, Wagner J, Häsler LM, Wild K, Skodras A, et al: Innate immune memory in the brain shapes neurological disease hallmarks. Nature 556: 332-338, 2018.

103. Schiepers OJG, Wichers MC and Maes M: Cytokines and major depression. Prog Neuropsychopharmacol Biol Psychiatry 29: 201-217, 2005.

104. Dowlati Y, Herrmann N, Swardfager W, Liu H, Sham L, Reim EK and Lanctôt KL: A meta-analysis of cytokines in major depression. Biol Psychiatry 67: 446-457, 2010.

105. Liu Y, Ho RCM and Mak A: The role of interleukin (IL)-17 in anxiety and depression of patients with rheumatoid arthritis. Int J Rheum Dis 15: 183-187, 2012.

106. Su JA, Chou SY, Tsai CS and Hung TH: Cytokine changes in the pathophysiology of poststroke depression. Gen Hosp Psychiatry 34: 35-39, 2012. 
107. Yirmiya R, Rimmerman $\mathrm{N}$ and Reshef R: Depression as a microglial disease. Trends Neurosci 38: 637-658, 2015.

108. Myint AM, Kim YK, Verkerk R, Scharpé S, Steinbusch H and Leonard B: Kynurenine pathway in major depression: Evidence of impaired neuroprotection. J Affect Disord 98: 143-151, 2007.

109. Tilleux S and Hermans E: Neuroinflammation and regulation of glial glutamate uptake in neurological disorders. J Neurosci Res 85: 2059-2070, 2007.

110. Tavares RG, Tasca CI, Santos CE, Alves LB, Porciúncula LO, Emanuelli T and Souza DO: Quinolinic acid stimulates synaptosomal glutamate release and inhibits glutamate uptake into astrocytes. Neurochem Int 40: 621-627, 2002.

111. Miller AH, Maletic V and Raison CL: Inflammation and its discontents: The role of cytokines in the pathophysiology of major depression. Biol Psychiatry 65: 732-741, 2009.

112. Salazar-Colocho P, Del Río J and Frechilla D: Neuroprotective effects of serotonin 5-HT $1 \mathrm{~A}$ receptor activation against ischemic cell damage in gerbil hippocampus: Involvement of NMDA receptor NR1 subunit and BDNF. Brain Res 1199: 159-166, 2008.

113. Davami MH, Baharlou R, Ahmadi Vasmehjani A, Ghanizadeh A, Keshtkar M, Dezhkam I and Atashzar MR: Elevated IL-17 and TGF- $\beta$ serum levels: A positive correlation between T-helper 17 cell-related pro-inflammatory responses with major depressive disorder. Basic Clin Neurosci 7: 137-142, 2016.

114. Beurel E, Harrington LE and Jope RS: Inflammatory T helper 17 cells promote depression-like behavior in mice. Biol Psychiatry 73: 622-630, 2013.

115. Li HL, Kostulas N, Huang YM, Xiao BG, van der Meide P, Kostulas V, Giedraitas V and Link H: IL-17 and IFN-gamma mRNA expression is increased in the brain and systemically after permanent middle cerebral artery occlusion in the rat. J Neuroimmunol 116: 5-14, 2001.

116. Zhang J, Mao X, Zhou T, Cheng X and Lin Y: IL-17A contributes to brain ischemia reperfusion injury through calpain-TRPC6 pathway in mice. Neuroscience 274: 419-428, 2014.

117. Kichev A, Rousset CI, Baburamani AA, Levison SW, Wood TL, Gressens P, Thornton $\mathrm{C}$ and Hagberg H: Tumor necrosis factor-related apoptosis-inducing ligand (TRAIL) signaling and cell death in the immature central nervous system after hypoxia-ischemia and inflammation. J Biol Chem 289: 9430-9439, 2014

118. Heymann MF, Herisson F, Davaine JM, Charrier C, Battaglia S, Passuti N, Lambert G, Gouëffic Y and Heymann D: Role of the OPG/RANK/RANKL triad in calcifications of the atheromatous plaques: Comparison between carotid and femoral beds. Cytokine 58: 300-306, 2012.

119. Nagy EE, Varga-Fekete T, Puskas A, Kelemen P, Brassai Z, Szekeres-Csiki K, Gombos T, Csanyi MC and Harsfalvi J: High circulating osteoprotegerin levels are associated with non-zero blood groups. BMC Cardiovasc Disord 16: 106, 2016.

120. Shimamura $M$, Nakagami H, Osako MK, Kurinami $H$, Koriyama $\mathrm{H}$, Zhengda P, Tomioka H, Tenma A, Wakayama $\mathrm{K}$ and Morishita R: OPG/RANKL/RANK axis is a critical inflammatory signaling system in ischemic brain in mice. Proc Natl Acad Sci USA 111: 8191-8196, 2014.

121. Kim HY and Han SH: Matrix metalloproteinases in cerebral ischemia. J Clin Neurol 2: 163-170, 2006.

122. Anuncibay-Soto B, Pérez-Rodriguez D, Santos-Galdiano M, Font-Belmonte E, Ugidos IF, Gonzalez-Rodriguez P Regueiro-Purriños M and Fernández-López A: Salubrinal and robenacoxib treatment after global cerebral ischemia. Exploring the interactions between ER stress and inflammation. Biochem Pharmacol 151: 26-37, 2018.

123. Ugidos IF, Santos-Galdiano M, Pérez-Rodríguez D, AnuncibaySoto B, Font-Belmonte E, López DJ, Ibarguren M, Busquets X and Fernández-López A: Neuroprotective effect of 2-hydroxy arachidonic acid in a rat model of transient middle cerebral artery occlusion. Biochim Biophys Acta Biomembr 1859: 1648-1656, 2017.

124. De los Reyes LM and Céspedes AE: Atorvastatin-meloxicam association inhibits neuroinflammation and attenuates the cellular damage in cerebral ischemia by arterial embolism. Biomedica 34: 366-378, 2014 (In Spanish).

125.Llorente IL, Landucci E, Pellegrini-Giampietro DE and Fernández-López A: Glutamate receptor and transporter modifications in rat organotypic hippocampal slice cultures exposed to oxygen-glucose deprivation: The contribution of cyclooxygenase-2. Neuroscience 292: 118-128, 2015.
126. Nagy E, Vajda E, Vari C, Sipka S, Fárr AM and Horváth E: Meloxicam ameliorates the cartilage and subchondral bone deterioration in monoiodoacetate-induced rat osteoarthritis. PeerJ 5: e3185, 2017.

127. Arafa HM, Abdel-Wahab MH, El-Shafeey MF, Badary OA and Hamada FM: Anti-fibrotic effect of meloxicam in a murine lung fibrosis model. Eur J Pharmacol 564: 181-189, 2007.

128. Hassan MH and Ghobara MM: Antifibrotic effect of meloxicam in rat liver: Role of nuclear factor kappa B, proinflammatory cytokines, and oxidative stress. Naunyn Schmiedebergs Arch Pharmacol 389: 971-983, 2016.

129. Honma S, Shinohara M, Takahashi N, Nakamura K, Hamano S, Mitazaki S, Abe S and Yoshida M: Effect of cyclooxygenase (COX)-2 inhibition on mouse renal interstitial fibrosis. Eur J Pharmacol 740: 578-583, 2014.

130. Csifo E, Nagy EE, Horvath E, Farr A and Muntean DL: Mid-term effects of meloxicam on collagen type II degradation in a rat osteoarthritis model induced by iodoacetate. Farmacia 63: 556-560, 2015

131. Sabogal-Guáqueta AM, Posada-Duque R, Cortes NC, Arias-Londoño JD and Cardona-Gómez GP: Changes in the hippocampal and peripheral phospholipid profiles are associated with neurodegeneration hallmarks in a long-term global cerebral ischemia model: Attenuation by Linalool. Neuropharmacology 135: $555-571,2018$

132. Horváth E, Oradan A and Chiriac L: Dobreanu M, Nagy EE, Voidăzan S, Berei R, Muntean DL and Hutanu A: Fish-oil preconditioning upregulates expression of splenic Arg1 positive M2 type macrophags and the Arg1/iNos2 ratio after experimental induced transient cerebral ischemia. Farmacia 67: 820-829, 2019.

133. Horvath E, Hutanu A, Oradan A, Chiriac L, Muntean DL, Nagy EE and Dobreanu M: N-3 polyunsaturated fatty acids induce granulopoiesis and early monocyte polarization in the bone marrow of a tMCAO rat model. Rev Rom Med Lab 27: 51-61, 2019.

134. Pentón-Rol G, Marín-Prida J and Falcón-Cama V: C-phycocyanin and phycocyanobilin as remyelination therapies for enhancing recovery in multiple sclerosis and ischemic stroke: A preclinical perspective. Behav Sci (Basel) 8: E158, 2018.

135. Alawieh A, Elvington A, Zhu H, Yu J, Kindy MS, Atkinson C and Tomlinson S: Modulation of post-stroke degenerative and regenerative processes and subacute protection by site-targeted inhibition of the alternative pathway of complement. J Neuroinflammation 12: 247, 2015.

136. Kopschina Feltes P, Doorduin J, Klein HC, Juárez-Orozco LE, Dierckx RA, Moriguchi-Jeckel CM and de Vries EF: Anti-inflammatory treatment for major depressive disorder: Implications for patients with an elevated immune profile and non-responders to standard antidepressant therapy. J Psychopharmacol 31: 1149-1165, 2017.

137. Akhondzadeh S, Jafari S, Raisi F, Nasehi AA, Ghoreishi A, Salehi B, Mohebbi-Rasa S, Raznahan M and Kamalipour A: Clinical trial of adjunctive celecoxib treatment in patients with major depression: A double blind and placebo controlled trial. Depress Anxiety 26: 607-611, 2009.

138. Abbasi SH, Hosseini F, Modabbernia A, Ashrafi M and Akhondzadeh S: Effect of celecoxib add-on treatment on symptoms and serum IL-6 concentrations in patients with major depressive disorder: Randomized double-blind placebo-controlled study. J Affect Disord 141: 308-314, 2012.

139. Tyring S, Gottlieb A, Papp K, Gordon K, Leonardi C, Wang A, Lalla D, Woolley M, Jahreis A, Zitnik R, et al: Etanercept and clinical outcomes, fatigue, and depression in psoriasis: Double-blind placebo-controlled randomised phase III trial. Lancet 367: 29-35, 2006.

140. Nemeth CL, Glasper ER, Harrell CS, Malviya SA, Otis JS and Neigh GN: Meloxicam blocks neuroinflammation, but not depressive-like behaviors, in HIV-1 transgenic female rats. PLoS One 9: e108399, 2014.

141. Liu J, Nolte K, Brook G, Liebenstund L, Weinandy A, Höllig A, Veldeman M, Willuweit A, Langen KJ, Rossaint R, et al: Post-stroke treatment with argon attenuated brain injury, reduced brain inflammation and enhanced M2 microglia/macrophage polarization: A randomized controlled animal study. Crit Care 23: 198, 2019.

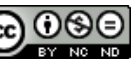

This work is licensed under a Creative Commons Attribution-NonCommercial-NoDerivatives 4.0 International (CC BY-NC-ND 4.0) License. 